\title{
A novel fast gas chromatography method for higher time resolution measurements of speciated monoterpenes in air
}

\author{
C. E. Jones ${ }^{1,2}$, S. Kato ${ }^{3}$, Y. Nakashima ${ }^{4}$, and Y. Kajii ${ }^{1,2}$ \\ ${ }^{1}$ Graduate School of Global Environmental Studies, Kyoto University, Yoshida-Honmachi, Sakyo-ku, Kyoto, 606-8501, Japan \\ ${ }^{2}$ Center for Regional Environmental Research, National Institute for Environmental Studies, Tsukuba City, \\ Ibaraki, 305-8506, Japan \\ ${ }^{3}$ Department of Applied Chemistry, Faculty of Urban Environmental Sciences, Tokyo Metropolitan University, \\ 1-1 Minami-Osawa, Hachioji, Tokyo, 192-0397, Japan \\ ${ }^{4}$ Department of Environmental and Natural Resource Science, Faculty of Agriculture, Tokyo University of Agriculture and \\ Technology, 3-5-8 Saiwai-cho, Fuchu, Tokyo, 183-8538, Japan
}

Correspondence to: C. E. Jones (jones.charlotte.7s@kyoto-u.ac.jp)

Received: 25 November 2013 - Published in Atmos. Meas. Tech. Discuss.: 17 December 2013

Revised: 26 March 2014 - Accepted: 27 March 2014 - Published: 15 May 2014

\begin{abstract}
Biogenic emissions supply the largest fraction of non-methane volatile organic compounds (VOC) from the biosphere to the atmospheric boundary layer, and typically comprise a complex mixture of reactive terpenes. Due to this chemical complexity, achieving comprehensive measurements of biogenic VOC (BVOC) in air within a satisfactory time resolution is analytically challenging. To address this, we have developed a novel, fully automated Fast Gas Chromatography (Fast-GC) based technique to provide higher time resolution monitoring of monoterpenes (and selected other $\mathrm{C}_{9}-\mathrm{C}_{15}$ terpenes) during plant emission studies and in ambient air. To our knowledge, this is the first study to apply a Fast-GC based separation technique to achieve quantification of terpenes in ambient air. Three chromatography methods have been developed for atmospheric terpene analysis under different sampling scenarios. Each method facilitates chromatographic separation of selected BVOC within a significantly reduced analysis time compared to conventional GC methods, whilst maintaining the ability to quantify individual monoterpene structural isomers. Using this approach, the $\mathrm{C}_{9}-\mathrm{C}_{15}$ BVOC composition of single plant emissions may be characterised within a $14.5 \mathrm{~min}$ analysis time. Moreover, in-situ quantification of 12 monoterpenes in unpolluted ambient air may be achieved within an $11.7 \mathrm{~min}$ chromatographic separation time (increasing to $19.7 \mathrm{~min}$ when simultaneous quantification of multiple oxygenated $\mathrm{C}_{9}-\mathrm{C}_{10}$ terpenoids is required, and/or when concentrations
\end{abstract}

of anthropogenic VOC are significant). These analysis times potentially allow for a twofold to fivefold increase in measurement frequency compared to conventional GC methods. Here we outline the technical details and analytical capability of this chromatographic approach, and present the first in-situ Fast-GC observations of 6 monoterpenes and the oxygenated BVOC (OBVOC) linalool in ambient air. During this field deployment within a suburban forest $\sim 30 \mathrm{~km}$ west of central Tokyo, Japan, the Fast-GC limit of detection with respect to monoterpenes was $4-5 \mathrm{ppt}$, and the agreement between Fast-GC and PTR-MS derived total monoterpene mixing ratios was consistent with previous GC/PTR-MS comparisons. The measurement uncertainties associated with the Fast-GC quantification of monoterpenes are $\leq 12 \%$, while larger uncertainties (up to $\sim 25 \%$ ) are associated with the OBVOC and sesquiterpene measurements.

\section{Introduction}

Volatile organic compounds (VOC) play a key role in tropospheric processes that influence air quality and climate forcing, such as ozone production and secondary organic aerosol (SOA) formation (Andreae and Crutzen, 1997; Sillman, 1999; Fuentes et al., 2000 and references therein). Biogenic VOC (BVOC) constitute the largest fraction of the total global non-methane VOC supplied to the planetary boundary 
layer (>90\% - Greenberg et al., 1999), with the global BVOC flux estimated to be of the order of $1100 \mathrm{Tg} \mathrm{C} \mathrm{yr}^{-1}$ (Guenther et al., 1995), compared to just 50-100 $\mathrm{Tg} \mathrm{C} \mathrm{yr}^{-1}$ anthropogenic VOC (Holzke et al., 2006). Furthermore, BVOC are typically highly reactive with respect to the atmospheric oxidants $\mathrm{OH}$ and $\mathrm{O}_{3}$ (atmospheric lifetimes range from minutes to days for monoterpenes, Atkinson and Arey, 2003), and hence in the presence of $\mathrm{NO}_{x}$ even relatively low concentrations of these trace gases can initiate efficient tropospheric ozone production cycles (Chameides et al., 1988).

Despite the potential impact of biogenic emissions with respect to both the global carbon cycle and local scale oxidant budgets, there are substantial uncertainties associated with the current understanding of BVOC-mediated tropospheric photochemistry. These uncertainties are highlighted by efforts to constrain measurements of the total $\mathrm{OH}$ reactivity of ambient air using concurrent trace gas observations. In forested regions, the directly measured total $\mathrm{OH}$ reactivity of boundary layer air (defined as the sum of the concentrations of each individual $\mathrm{OH}$ sink multiplied by their respective reaction rate coefficients) is frequently greater than the equivalent estimated $\mathrm{OH}$ reactivity, derived from simultaneous VOC observations (Di Carlo et al., 2004; Sinha et al., 2010; Nölscher et al., 2012; Edwards et al., 2013). This discrepancy between measured and calculated $\mathrm{OH}$ reactivity reveals the presence of an unidentified $\mathrm{OH}$ sink (or sinks) within the forest boundary layer, which may potentially be attributed to unmeasured primary BVOC emissions (Di Carlo et al., 2004; Sinha et al., 2010), unmeasured oxidation products of primary BVOC following atmospheric processing (Lou et al., 2010; Taraborrelli et al., 2012; Edwards et al., 2013), or a combination of these sources (Nölscher et al., 2012). Holzinger et al. (2005) observed large quantities of BVOC oxidation products within a Ponderosa pine forest, which implied significant unmeasured primary BVOC emissions within this region. As such, it is apparent that a more detailed characterisation of the ambient air BVOC composition is necessary in order to effectively constrain the forest boundary layer oxidant budget. Furthermore, recent studies suggest that BVOC potentially contribute a significant fraction of the boundary layer ozone formation within urban centres (particularly during summertime pollution episodes, e.g. Lee et al., 2006; Curci et al., 2009), providing motivation for in situ observations of these trace gases in polluted atmospheres with some biogenic influence (such as a city surrounded by forest), as well as within remote forest air. However, the chemical complexity of air influenced by biogenic emissions makes achieving comprehensive measurements of BVOC in these environments analytically challenging.

Emissions from vegetation typically comprise a vast number of terpenes with a wide range of volatilities, including isoprene $\left(\mathrm{C}_{5} \mathrm{H}_{8}\right)$, monoterpenes $\left(\mathrm{C}_{10} \mathrm{H}_{16}\right)$, sesquiterpenes $\left(\mathrm{C}_{15} \mathrm{H}_{24}\right)$ and numerous oxygenated terpenoids (Kesselmeier and Staudt, 1999). Each class of terpene consists of multiple structural isomers, which are indistinguishable by some analytical techniques, yet have greatly varying reactivities with respect to atmospheric oxidants (see Table 1 and references therein). As such, quantification of each individual isomer is fundamental to achieving a comprehensive characterisation of the impact of BVOC upon the oxidation capacity of the troposphere. Furthermore, BVOC emission rates are generally dependent upon environmental conditions such as solar radiation, temperature, humidity and $\mathrm{CO}_{2}$ concentration, which often results in emission profiles with substantial diurnal variability (Kesselmeier and Staudt, 1999), as well as a potential sensitivity to long-term changes in climate. As a consequence of these variable emission rates, and the relatively short lifetimes of many terpenes with respect to atmospheric oxidants, ambient air concentrations of BVOC such as monoterpenes typically demonstrate significant short-term variability, which necessitates a high time-resolution measurement technique. Established measurement techniques for in situ BVOC monitoring typically offer a trade-off between sample frequency and speciation. Detailed information regarding chemical composition may be obtained via conventional gas chromatography methods (GC-FID and GCMS) which can quantify individual terpene isomers, but with a limited sample frequency (typically one 10-30 min averaged sample, every $\sim 50-60 \mathrm{~min}-$ e.g Bouvier-Brown et al., 2009; Jones et al., 2011; Hopkins et al., 2011). In contrast, near real-time terpene observations may be obtained by proton transfer reaction (PTR) mass spectrometry techniques (e.g. Rinne et al., 2005; Langford et al., 2010), however this approach does not provide quantification of individual structural isomers. As a consequence of the complex chemical composition of air influenced by biogenic emissions, and the associated instrument limitations, observations of BVOC in ambient air are limited in comparison with those of anthropogenic VOC.

To address the current instrumental limitations, we have developed a fully automated fast gas chromatography - flame ionisation detection (Fast-GC-FID) method for quantification of a range of $\mathrm{C}_{9}-\mathrm{C}_{15} \mathrm{BVOC}$, including multiple structural isomers.

Previous studies have utilised Fast-GC based techniques for a variety of applications, including quantitative analysis of methanol and $\mathrm{C}_{2}-\mathrm{C}_{4}$ carbonyls in ambient air (Apel et al., 2003), analysis of monoaromatic VOC in gasoline (Hamilton and Lewis, 2003), and quantifying limonene emissions within a plant chamber (Yassaa et al., 2010). Fast-GC methods have also been employed to provide qualitative analysis of the BVOC composition of essential oils (e.g. White, 2009), and for various forensic applications (Eckenrode, 2001). However, to our knowledge, this is the first study to apply Fast-GC separation to the quantitative analysis of terpenes in ambient air. The Fast-GC based methods presented here retain the separation capability of conventional gas chromatography, yet offer significantly improved measurement frequency. Here we outline the instrument specifications and present the first applications of Fast-GC for BVOC analysis 
Table 1. BVOC targeted for quantification by Fast-GC, their rate constants with respect to reaction with the atmospheric oxidants OH and $\mathrm{O}_{3}$, and limits of detection (LOD) for Fast-GC analysis of these BVOC in plant chamber studies and in ambient air.

\begin{tabular}{|c|c|c|c|c|c|c|c|}
\hline & $\begin{array}{l}k_{\mathrm{OH}} \times 10^{12} \\
\left(\mathrm{~cm}^{3} \mathrm{molec}^{-1} \mathrm{~s}^{-1}\right)\end{array}$ & $\begin{array}{l}k_{\mathrm{O}_{3}} \times 10^{18} \\
\left(\mathrm{~cm}^{3} \mathrm{molec}^{-1} \mathrm{~s}^{-1}\right)\end{array}$ & $\begin{array}{l}\text { LOD (ppt) } \\
\text { (a) AMBIENT } \\
\text { (b) CHAMBER }\end{array}$ & & $\begin{array}{l}k_{\mathrm{OH}} \times 10^{12} \\
\left(\mathrm{~cm}^{3} \mathrm{molec}^{-1} \mathrm{~s}^{-1}\right)\end{array}$ & $\begin{array}{l}k_{\mathrm{O}_{3}} \times 10^{18} \\
\left(\mathrm{~cm}^{3} \mathrm{molec}^{-1} \mathrm{~s}^{-1}\right)\end{array}$ & $\begin{array}{l}\text { LOD (ppt) } \\
\text { (a) AMBIENT } \\
\text { (b) CHAMBER }\end{array}$ \\
\hline $\begin{array}{l}\text { Monoterpenes } \\
\alpha \text {-pinene }\end{array}$ & 53.7 & 86.6 & $\begin{array}{l}\text { (a) } 4 \\
\text { (b) } 10\end{array}$ & $\begin{array}{l}\text { Oxygenated terpenes } \\
\alpha \text {-terpineol }\end{array}$ & $190.0^{\mathrm{c}}$ & $300.0^{c}$ & $\begin{array}{l}\text { (a) } 4 \\
\text { (b) }-\end{array}$ \\
\hline Camphene & 53.0 & 0.90 & $\begin{array}{l}\text { (a) } 4 \\
\text { (b) } 10\end{array}$ & Linalool & $160.0^{\mathrm{d}}$ & $430.0^{\mathrm{d}}$ & $\begin{array}{l}\text { (a) } 4 \\
\text { (b) } 8\end{array}$ \\
\hline$\beta$-pinene & 78.9 & 15.0 & $\begin{array}{l}\text { (a) } 4-5 \\
\text { (b) } 9\end{array}$ & Nopinone & $17.0^{\mathrm{e}}$ & $<0.005^{\mathrm{e}}$ & $\begin{array}{l}\text { (a) } 5 \\
\text { (b) - }\end{array}$ \\
\hline Myrcene & 215.0 & 86.6 & $\begin{array}{l}\text { (a) } 4-5 \\
\text { (b) } 9\end{array}$ & Limonene oxide & $11.1^{\mathrm{a}}$ & $<0.15^{\mathrm{b}}$ & $\begin{array}{l}\text { (a) } 5 \\
\text { (b) } 8\end{array}$ \\
\hline$\alpha$-phellandrene & 313.0 & 2980.0 & $\begin{array}{l}\text { (a) } 5 \\
\text { (b) } 11\end{array}$ & Methyl chavicol & $54.0^{\mathrm{f}}$ & $12.0^{\mathrm{f}}$ & $\begin{array}{l}\text { (a) } 4 \\
\text { (b) } 8\end{array}$ \\
\hline$\alpha$-terpinene & 363.0 & 21100.0 & $\begin{array}{l}\text { (a) } 5 \\
\text { (b) } 10\end{array}$ & Terpinen-4-ol & 170.0 & 250.0 & $\begin{array}{l}\text { (a) } 4 \\
\text { (b) } 8\end{array}$ \\
\hline$\Delta$-3-carene & 88.0 & 37.0 & $\begin{array}{l}\text { (a) } 5 \\
\text { (b) } 11\end{array}$ & Sesquiterpenes & & & \\
\hline Limonene & 171.0 & 200.0 & $\begin{array}{l}\text { (a) } 4 \\
\text { (b) } 9\end{array}$ & $\alpha$-copaene & 90.0 & 160.0 & $\begin{array}{l}\text { (a) }- \\
\text { (b) } 11\end{array}$ \\
\hline Ocimene & 252.0 & 540.0 & $\begin{array}{l}\text { (a) } 4 \\
\text { (b) } 9\end{array}$ & $\alpha$-cedrene & 67.0 & 28.0 & $\begin{array}{l}\text { (a) }- \\
\text { (b) } 12\end{array}$ \\
\hline$\gamma$-terpinene & 177.0 & 140.0 & $\begin{array}{l}\text { (a) } 4 \\
\text { (b) } 9\end{array}$ & $\beta$-caryophyllene & 197.0 & 11600.0 & $\begin{array}{l}\text { (a) }- \\
\text { (b) } 12\end{array}$ \\
\hline terpinolene & 225.0 & 1880.0 & $\begin{array}{l}\text { (a) } 4 \\
\text { (b) }-\end{array}$ & $\alpha$-humulene & 293.0 & 11700.0 & $\begin{array}{l}\text { (a) }- \\
\text { (b) } 11\end{array}$ \\
\hline$p$-cymene & $15.1^{\mathrm{a}}$ & $<0.05^{\mathrm{b}}$ & $\begin{array}{l}\text { (a) } 5 \\
\text { (b) }-\end{array}$ & & & & \\
\hline
\end{tabular}

Note that a range of ambient air LOD's are reported where the value is different for the two chromatography methods. LOD's for plant chamber analyses correspond to a sample volume of $350 \mathrm{~mL}$. Rate constants are from Atkinson (1997) unless otherwise stated. ${ }^{\mathrm{a}}$ from Corchnoy and Atkinson (1990); ${ }^{\mathrm{b}}$ from Atkinson et al. (1990); ${ }^{\mathrm{c}}$ from Wells (2005);

${ }^{\mathrm{d}}$ from Atkinson et al. (1995); ${ }^{\mathrm{e}}$ from Calogirou et al. 1999; ${ }^{\mathrm{f}}$ from Bouvier-Brown et al. (2009).

in plant emission chamber studies and in situ ambient air monitoring.

\section{Methods}

The BVOC targeted for Fast-GC analysis in this study include monoterpenes, $\mathrm{C}_{9}-\mathrm{C}_{10}$ oxygenated terpenoids, and sesquiterpenes (individual structural isomers are listed in Table 1). A Fast-GC system has been developed for BVOC quantification under two scenarios; (1) to quantify these $\mathrm{BVOC}$ in emissions from a single plant during chamber experiments; (2) to monitor mixing ratios of BVOC in ambient air. The experimental details regarding sample preconcentration, chromatography and calibration for the quantitative analysis of these trace gases using a Fast-GC instrument are outlined in the following sub-sections.

\subsection{BVOC pre-concentration}

Due to the relatively low concentrations (ppt-ppb) of BVOC in both plant chamber emissions and ambient air, it is necessary to pre-concentrate these trace gases prior to GC analysis. To achieve this, a Unity2 Thermal Desorber with 3 channel
Airserver (Markes, UK) containing a Peltier-cooled Tenax cold trap is used in-conjunction with the Fast-GC instrument. Tenax sorbent was selected for this application due to its hydrophobicity and ability to trap $\mathrm{VOC}>\mathrm{C}_{6}$ at ambient temperatures, which is particularly advantageous when sampling air in humid environments, where high moisture levels may give rise to instrument difficulties. In addition, previous studies have reported quantitative pre-concentration of volatile and semi-volatile terpenes using this sorbent material (e.g. Bouvier-Brown et al., 2009). The cold trap is Peltier-cooled to $20^{\circ} \mathrm{C}$ during sampling in order to effectively trap $\mathrm{C}_{6}-\mathrm{C}_{15}$ VOC, whilst minimising the amount of water vapour retained on the trap. Following a fixed sampling time (for details see below), the trap is back-flushed with dry helium gas at $30 \mathrm{~mL} \mathrm{~min}^{-1}$ for $1-2 \mathrm{~min}$ in order to remove moisture, before rapidly heating $\left(\sim 100^{\circ} \mathrm{C} \mathrm{s}^{-1}\right)$ to $300^{\circ} \mathrm{C}$ while helium carrier gas is diverted through the trap, such that the pre-concentrated VOC are desorbed and delivered to the GC column via a heated transfer line (deactivated silica capillary, $\left.130^{\circ} \mathrm{C}\right)$. The Fast-GC instrument used for this study (300 Series GC, Ellutia - for details see Sect. 2.2) contains a unique automatic column insertion (ACI) mechanism, whereby the GC column is not manually connected 


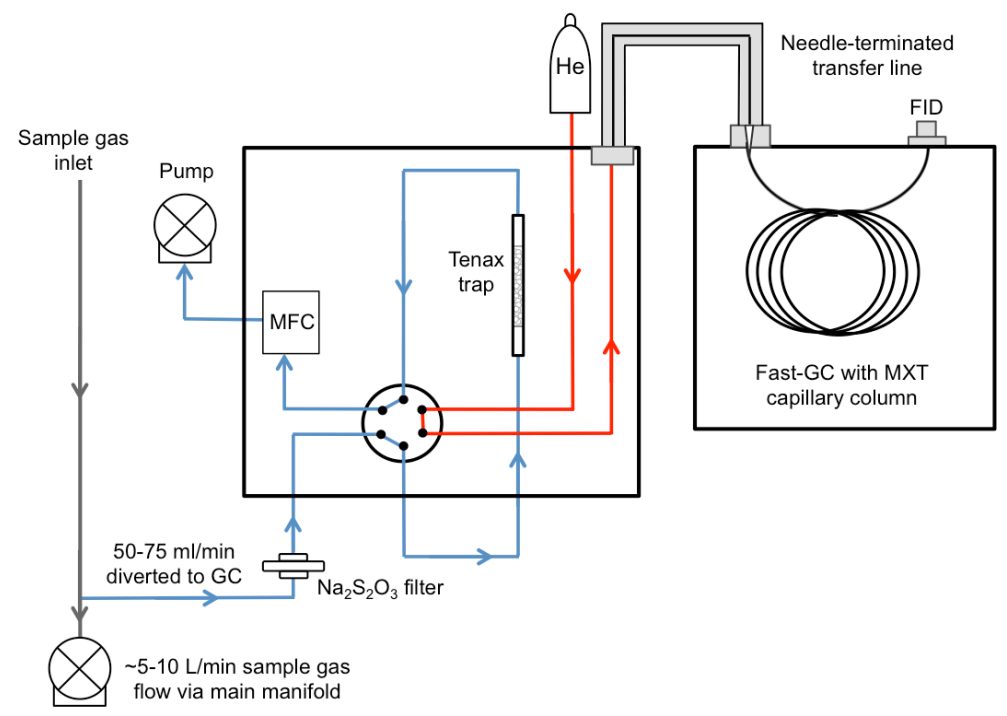

Fig. 1. Schematic of the Fast-GC instrument, thermal desorber and needle-terminated transfer line, in the air sampling configuration. The sample gas flow path is illustrated in blue; helium carrier gas flow within the thermal desorber is shown in red.

to the heated transfer line and detector using conventional fittings, but is mechanically inserted via an automatic mechanism. This means that pre-concentrated VOC cannot be delivered from the Unity2 Thermal Desorber cold trap via a conventional silica transfer line inserted through the GC injector port and connected directly via a union fitting to the GC column. Instead, a modified transfer line/GC column interface is utilised; a "needle-terminated" transfer line (Agilent) houses a conventional $0.25 \mathrm{~mm}$ fused silica capillary within an insulated cover which is fitted with a needle connection at the GC terminal. This needle is simply inserted through the septum of the GC injector port, which is heated to $210^{\circ} \mathrm{C}$ under normal operating conditions. This set-up (outlined in Fig. 1) allows for continuous automated sampling of VOC in air.

Sampling conditions were optimised for pre-concentration of $\mathrm{C}_{9}-\mathrm{C}_{15}$ BVOCs using an in-house prepared gaseous mixture containing $\sim 0.5-1.5 \mathrm{ppb}$ of each BVOC diluted in nitrogen (for details, see Sect. 2.3). All trapping efficiency tests were performed within a $6 \mathrm{~h}$ period, and quantitative trapping was achieved for sample volumes of up to $1.5 \mathrm{~L}$, with a flow rate of $75 \mathrm{~mL} \mathrm{~min}^{-1}$. Sampling parameters for the analysis of BVOC in single plant emissions and in ambient air were selected in light of these tests, based upon the required instrument sensitivity and sampling frequency for each application; the comparatively higher concentrations of BVOC in plant chamber air typically allow a shorter sampling time $\left(5-7 \mathrm{~min} \times 50 \mathrm{~mL} \mathrm{~min}^{-1}=250-350 \mathrm{~mL}\right.$ sample volume), while the generally lower BVOC concentrations in ambient air necessitate a larger sample volume $\left(10 \mathrm{~min} \times 75 \mathrm{~mL} \mathrm{m^{-1 }}=750 \mathrm{~mL}\right.$ sample volume $)$. As a general rule, the sampling period is minimised as much as possible in order to fully utilise the high time resolution facilitated by the Fast-GC technique, as well as to limit the amount of water retained on the trap.

\subsection{Chromatography methods}

In principle, fast gas chromatography may be achieved through the use of a relatively short GC column $(\sim 5-20 \mathrm{~m})$, fast temperature ramp rates $\left(\sim 20-200^{\circ} \mathrm{C} \mathrm{min}^{-1}\right)$ and high carrier gas linear velocities $\left(\sim 60-120 \mathrm{~cm} \mathrm{~s}^{-1}\right)$. Purpose-built Fast-GC instruments typically employ direct resistive heating of the capillary column, which negates the need for a large GC oven and enables rapid heating during chromatographic separation, as well as faster post-separation cooling. The rapid heating and cooling of these columns contributes to an overall cycle time (defined as the time interval between the start of two consecutive measurements) that is substantially reduced in comparison with conventional GC methods. While these chromatography conditions may potentially lead to some reduction in separation efficiency, this can be offset to some extent by using narrow i.d. columns and a thin film stationary phase coating. Moreover, the combination of fast temperature ramps and high carrier gas flow velocities generates exceptionally sharp chromatographic peaks; consequently, while the absolute peak to peak separation between two analytes may be reduced, baseline resolution is often maintained due to a reduction in peak widths.

In order to quantify BVOC in air under several different composition scenarios, three distinct chromatography methods have been developed. The GC_CHAMBER method has been designed for analysis of $\mathrm{C}_{10}-\mathrm{C}_{15}$ BVOC in plant chamber air; the GC_AMBIENT I method was optimised for quantification of individual monoterpene structural isomers in unpolluted ambient air; the GC_AMBIENT II 
method facilitates analysis of $\mathrm{C}_{9}$ and $\mathrm{C}_{10}$ BVOC in ambient air influenced by both biogenic and anthropogenic emissions. In all cases, chromatographic separation of the monoterpene structural isomers was prioritised, with analysis of other terpenes considered a secondary objective. A 300 Series Gas Chromatograph (Ellutia) was utilised for all analyses, in conjunction with a resistively heated stainless steel capillary column (Restek) and helium carrier gas. The GC_CHAMBER chromatography method was developed using a $20 \mathrm{~m} \times 0.18 \mathrm{~mm}$ i.d. non-polar MXT-1 column ( $0.4 \mu \mathrm{m}$ film thickness), while a $15 \mathrm{~m} \times 0.25 \mathrm{~mm}$ i.d. nonpolar MXT-5 column $(0.25 \mu \mathrm{m}$ film thickness) is employed for analysis of BVOC in ambient air. Direct resistive heating of the inert coated steel capillary columns facilitates rapid heating during analysis, as well as rapid post-analysis cooling. Resistively heating the column also negates the need for a conventional GC oven, and as a result the $300 \mathrm{Se}-$ ries GC is smaller and lighter than standard GC systems (instrument footprint $=320 \mathrm{~mm} \times 370 \mathrm{~mm}$; weight $=7.5 \mathrm{~kg}$ ). Details of the three chromatography methods developed in this study are outlined in the following sections, and chromatograms recorded using each method are presented in Figs. 2-4. The relevant temperature programmes and carrier gas flow velocities are also illustrated in Figs. 2-4, and are summarised in Table 2. It should be noted that during the initial method development and testing period, BVOC-rich air (from single plant emissions and ambient air) was simultaneously analysed by Fast-GC and sampled into silcosteel canisters for independent offline analysis by conventional GC-FID and/or GC-MS, in order to support BVOC peak identification and/or quantification.

\subsubsection{Chromatography for plant chamber air analysis}

Single plant chamber studies represent a simplified scenario for measuring BVOC in air, since the BVOC composition is limited to primary emissions from one plant species, while mixing ratios of non-biogenic VOC are below the instrument detection limit, and the formation of BVOC oxidation products is minimised due to the absence of significant levels of atmospheric oxidants within the chamber. Furthermore, dilution of emitted BVOC within the enclosure is limited, and as such, single plant chamber emissions are relatively high concentration $(\sim \mathrm{ppb})$, low component BVOC mixtures, and thus are potentially well suited to fast gas chromatographic separation. That said, the presence of multiple terpene structural isomers with similar physical properties (boiling point, polarity) does limit the separation capacity to some extent, and extensive method development was carried out in order to utilise the capability of Fast-GC to minimise analysis time, whilst maintaining effective chromatographic separation of these complex BVOC mixtures.

The GC_CHAMBER chromatography method utilises a Fast-GC based approach to achieve separation of a number of monoterpenes and sesquiterpenes within a $14.5 \mathrm{~min}$ analysis
Table 2. Carrier gas flow velocities and temperature programmes utilised during Fast-GC analysis of BVOC in ambient air and single plant emissions.

\begin{tabular}{|c|c|c|c|c|}
\hline & $\begin{array}{c}\text { Upper flow } \\
\text { velocity } \\
\left(\mathrm{cm} \mathrm{s}^{-1}\right)\end{array}$ & $\begin{array}{r}\text { Upper } \\
\text { temperature } \\
\left({ }^{\circ} \mathrm{C}\right)\end{array}$ & $\begin{array}{r}\text { Temperature } \\
\text { ramp rate } \\
\left({ }^{\circ} \mathrm{C} \mathrm{min}{ }^{-1}\right)\end{array}$ & $\begin{array}{l}\text { Hold time } \\
(\min )\end{array}$ \\
\hline \multicolumn{5}{|c|}{ GC_CHAMBER } \\
\hline Initial & 60 & 40 & - & 2.0 \\
\hline Ramp 1 & 80 & 110 & 11 & 0 \\
\hline Ramp 2 & 70 & 160 & 42 & 0 \\
\hline Ramp 3 & 65 & 200 & 9 & 0.5 \\
\hline \multicolumn{3}{|c|}{ Total analysis time } & & $14.5 \mathrm{~min}$ \\
\hline \multicolumn{3}{|c|}{ Total measurement cycle time } & & $16.5 \mathrm{~min}$ \\
\hline \multicolumn{5}{|c|}{ GC_AMBIENT I } \\
\hline Initial & 52 & 39 & - & 2.0 \\
\hline Ramp 1 & 56 & 46 & 6 & 0.4 \\
\hline Ramp 2 & 70 & 72 & 6 & 0.2 \\
\hline Ramp 3 & 90 & 85 & 18 & 0 \\
\hline Ramp 4 & 85 & 125 & 40 & 0 \\
\hline Ramp 5 & 75 & 215 & 55 & 0.2 \\
\hline \multicolumn{3}{|c|}{ Total analysis time } & & $11.7 \mathrm{~min}$ \\
\hline \multicolumn{3}{|c|}{ Total measurement cycle time } & & $13.7 \mathrm{~min}$ \\
\hline \multicolumn{5}{|c|}{ GC_AMBIENT II } \\
\hline Initial & 51 & 38 & - & 2.0 \\
\hline Ramp 1 & 55 & 44 & 1 & 0.2 \\
\hline Ramp 2 & 75 & 64 & 5 & 2.8 \\
\hline Ramp 3 & 88 & 94 & 15 & 0 \\
\hline Ramp 4 & 85 & 125 & 35 & 0 \\
\hline Ramp 5 & 75 & 215 & 75 & 0.4 \\
\hline \multicolumn{3}{|c|}{ Total analysis time } & & $19.7 \mathrm{~min}$ \\
\hline \multicolumn{3}{|c|}{ Total measurement cycle time } & & $21.8 \mathrm{~min}$ \\
\hline
\end{tabular}

period (resulting in a 16.5 min cycle time, see Table 2). Moderately fast chromatography conditions are employed throughout the $\mathrm{C}_{10}$ and $\mathrm{C}_{15}$ elution periods (temperature ramps of 11 and $9{ }^{\circ} \mathrm{C} \mathrm{min}^{-1}$ respectively) to ensure resolution of the multiple structural isomers, while faster chromatography (temperature ramp of $42^{\circ} \mathrm{C} \mathrm{min}^{-1}$ ) is utilised during other periods, in order to minimise the total analysis time. The GC_CHAMBER method facilitates quantification of the monoterpenes $\alpha$-pinene, camphene, $\beta$ pinene, myrcene, $\alpha$-phellandrene, $\Delta$-3-carene, $\alpha$-terpinene, limonene, ocimene and $\gamma$-terpinene (note ocimene and $\gamma$ terpinene are not shown in Fig. 2), the $\mathrm{C}_{10}$ oxygenated terpenoids linalool, limonene oxide and methyl chavicol (methyl chavicol not shown in Fig. 2) and sesquiterpenes $\alpha$-copaene, $\alpha$-cedrene, $\beta$-caryophyllene and $\alpha$-humulene, within a total measurement cycle time of $16.5 \mathrm{~min}$. Limitations of this method include the partial separation of the chromatographic peak pairs $\Delta-3$-carene and $\alpha$-terpinene, and $\alpha$-cedrene and $\beta$-caryophyllene. Resolution of the $\Delta-3$ carene and $\alpha$-terpinene peaks is generally sufficient to provide quantification, albeit with increased uncertainty (see Sect. 2.3), whereas generally only the combined $\alpha$-cedrene and $\beta$-caryophyllene mixing ratio can be reported. Figure 2 outlines details of the GC_CHAMBER method, and shows 

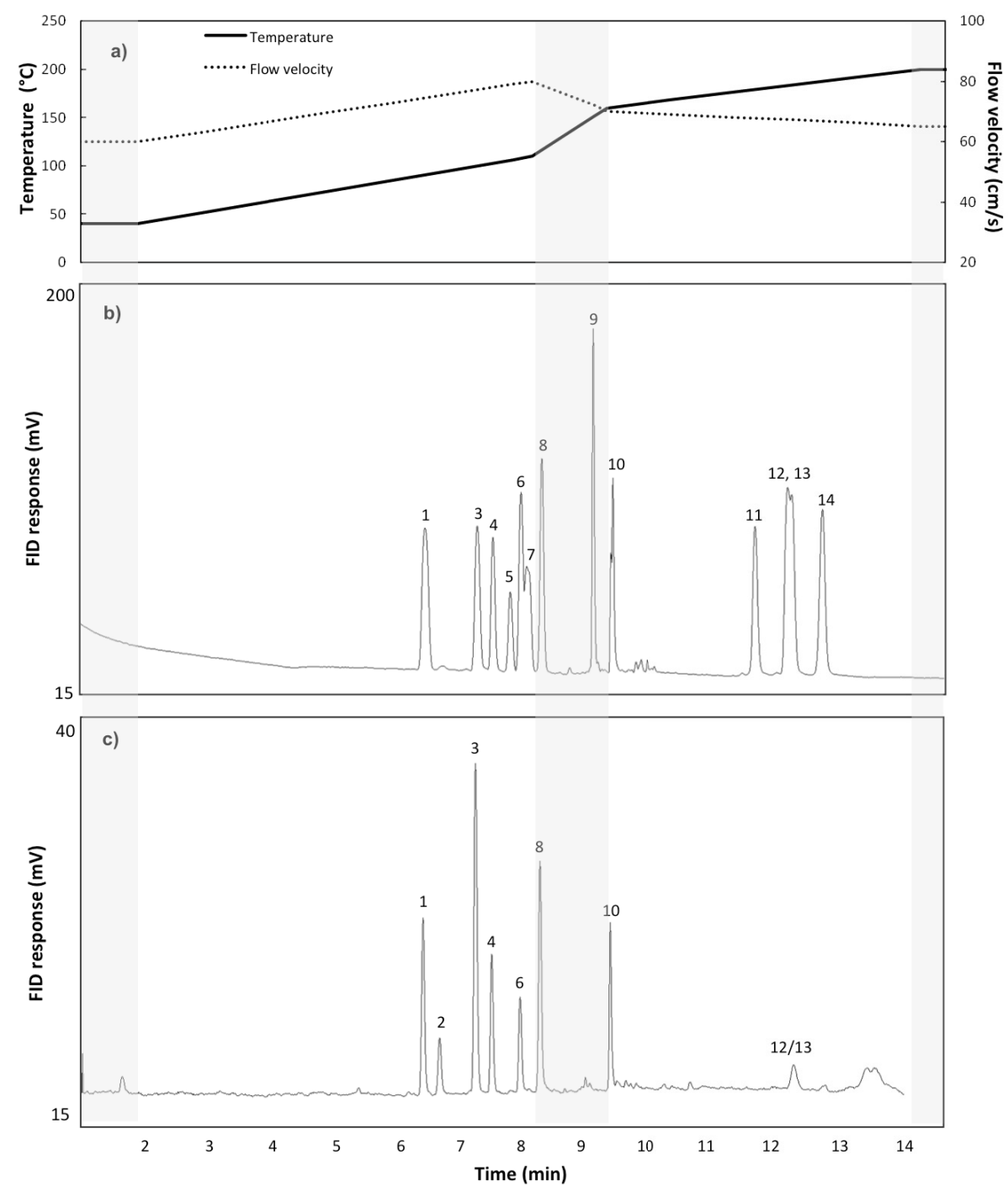

Fig. 2. (a) shows the temperature and carrier gas flow velocity programmes used for the GC_CHAMBER method. (b) shows a chromatographic trace recorded using the GC_CHAMBER method for analysis of BVOC in liquid standard $\left(\sim 2.0-8.0 \mathrm{mg} \mathrm{L}^{-1}\right.$ terpenes in isop-propyl alcohol). (c) is a chromatogram resulting from analysis of BVOC in air during a white spruce (Picea glauca) plant emission study (see Sect. 3.1 for details). Chromatographic peaks correspond to the following BVOC; $\alpha$-pinene(1), camphene(2), $\beta$-pinene(3), myrcene(4), $\alpha$-phellandrene(5), $\Delta$-3-carene(6), $\alpha$-terpinene(7), limonene(8), linalool(9), limonene oxide(10), $\alpha$-copaene(11), $\alpha$-cedrene(12), $\beta$-caryophyllene(13), $\alpha$-humulene(14). Alternate shaded regions highlight changes in chromatography parameters (for more details, see Table 2).

chromatograms generated using this method for analysis of a terpene liquid standard (Fig. 2b), and emissions from a white spruce plant (Fig. 2c, see Sect. 3.1 for more details).

\subsubsection{Chromatography for ambient air analysis}

In contrast to single plant emissions, the VOC composition of ambient air is generally much more complex, and may potentially comprise a large number of primary BVOC emitted from a variety of tree species, multiple oxidation products resulting from atmospheric processing of primary BVOC, and anthropogenic VOC. Analysis of BVOC in ambient air therefore necessitates a more sophisticated chromatographic approach.

In clean air with very little to no anthropogenic influence (such as remote forest sites), the GC_AMBIENT I chromatography method may be used to determine the ambient air monoterpene composition. This method provides efficient separation of the chromatographic peaks corresponding to the monoterpenes $\alpha$-pinene, camphene, $\beta$ pinene, myrcene, $\alpha$-phellandrene, $\Delta$-3-carene, $\alpha$-terpinene, limonene, ocimene, $\gamma$-terpinene and terpinolene, and the $\mathrm{C}_{10}$ alkyl benzene p-cymene (sometimes classed as a monoterpene), within an $11.7 \mathrm{~min}$ analysis time (13.7 min cycle 

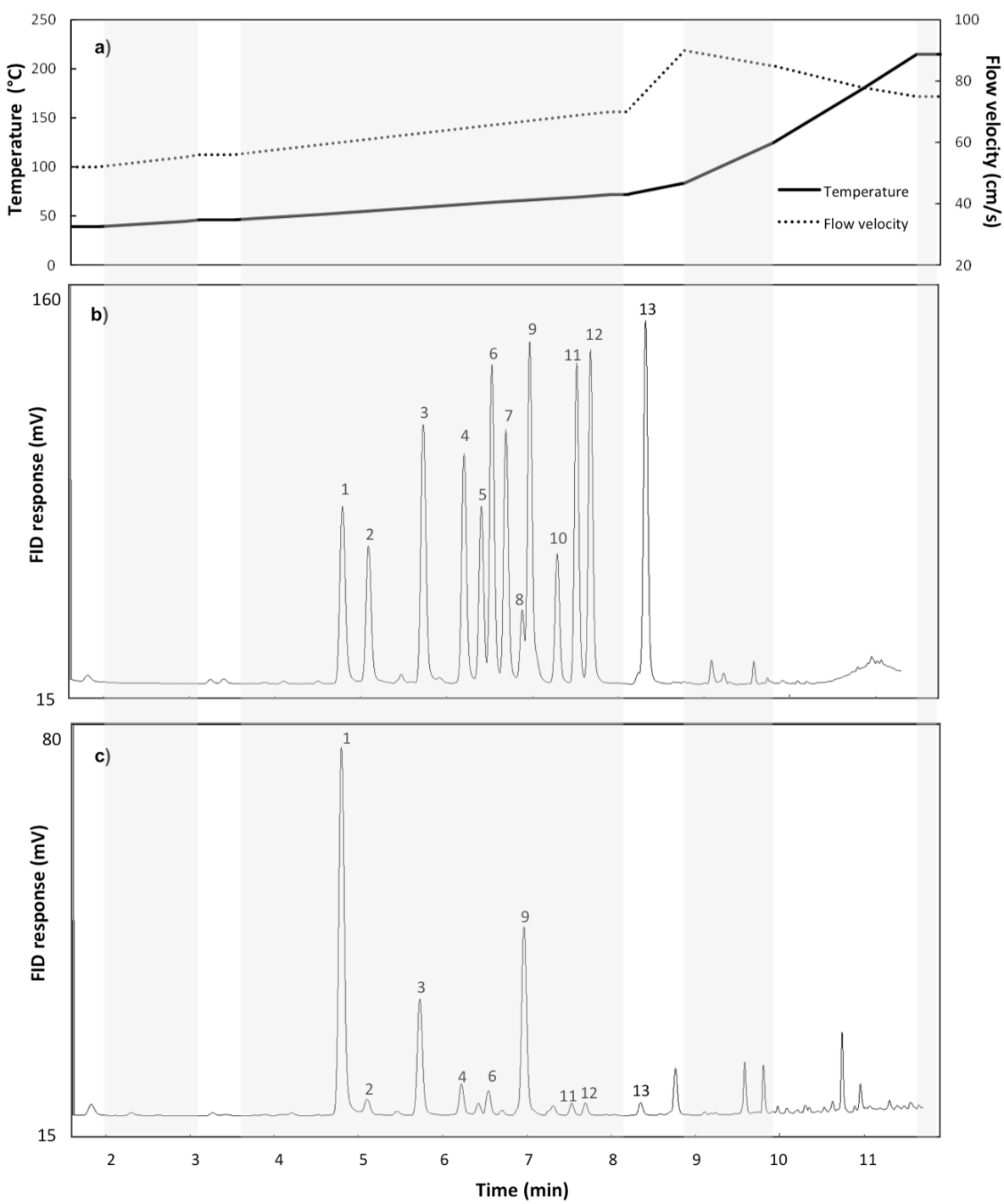

Fig. 3. (a) shows the GC_AMBIENT I method temperature and carrier gas flow velocity programmes. (b) shows a chromatographic trace recorded using the GC_AMBIENT I method for analysis of a monoterpene liquid standard $\left(\sim 1.0-5.0 \mathrm{mg} \mathrm{L}^{-1}\right.$ monoterpenes in isop-propyl alcohol). (c) shows a chromatogram recorded using this method to analyse monoterpenes in a discrete canister sample containing clean air (anthropogenic VOC close to or below instrument detection limit) from a pine forest in Ibaraki prefecture, Japan. Chromatographic peaks correspond to the following monoterpenes; $\alpha$-pinene(1), camphene(2), $\beta$-pinene(3), myrcene(4), $\alpha$-phellandrene(5), $\Delta$-3-carene(6), $\alpha$-terpinene(7), p-cymene(8), limonene(9), ocimene(10), unidentified terpene(11), $\gamma$-terpinene(12), terpinolene(13). Alternate shaded regions highlight changes in chromatography parameters (for more details, see Table 2).

time). Using this method, the majority of chromatographic peaks are fully baseline resolved (exceptions being a very small amount of overlap between the $\alpha$-phellandrene and $\Delta$ 3-carene peaks, as well as a slightly greater degree of overlap between the p-cymene and limonene peaks), allowing individual quantification of these $12 \mathrm{C}_{10}$ terpenes.

In polluted air, GC analysis of BVOC requires resolution of a vast number of closely eluting chromatographic peaks - including numerous anthropogenic VOC, as well as multiple terpene isomers - and as such, we have found that very fast chromatography is not a viable technique for quantification of terpenes in air influenced by both biogenic and anthropogenic emissions. However, we demonstrate that by combining periods of moderately fast chromatography, more conventional chromatography conditions, and isothermal separation, satisfactory separation of a range of monoterpenes and oxygenated $\mathrm{C}_{9}-\mathrm{C}_{10}$ terpenoids can be achieved. For these more complex compositions, the GC_AMBIENT II method was developed to facilitate chromatographic separation of the monoterpenes listed above, as well as the oxygenated terpenes linalool, $\alpha$-terpineol, limonene oxide, terpinen-4-ol, methyl chavicol, and the 

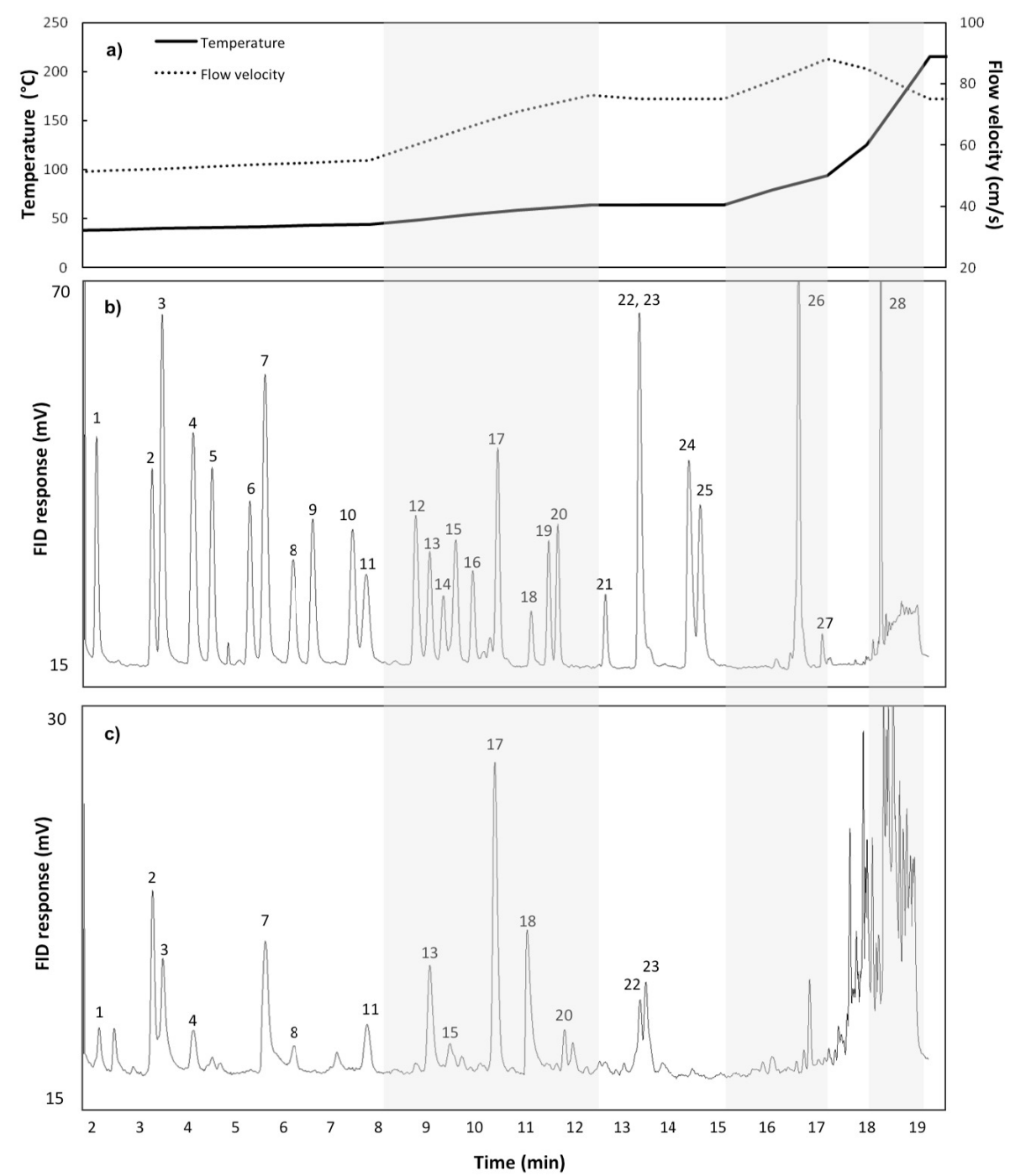

Fig. 4. (a) shows the temperature and carrier gas flow velocity programmes used for the GC_AMBIENT II method. (b) shows a chromatographic trace recorded using the GC_AMBIENT II method for analysis of VOC within an in-house prepared gas standard (containing $\sim$ ppb concentrations of BVOC and common anthropogenic VOC). (c) shows a chromatogram resulting from analysis of VOC in ambient air within a suburban forest (see Sect. 3.2.2 for details). Chromatographic peaks are labelled as follows; ethylbenzene(1), p-xylene $+\mathrm{m}-\mathrm{xylene}(2)$, styrene(3), o-xylene(4), nonane(5), iso-propylbenzene(6), $\alpha$-pinene(7), camphene(8), n-propylbenzene(9), 1,3,5-trimethylbenzene(10), $\beta$ pinene(11), 1,2,4-trimethylbenzene(12), myrcene(13), $\alpha$-phellandrene(14), $\Delta$-3-carene(15), $\alpha$-terpinene(16), limonene(17), ocimene(18), unidentified terpene(19), $\gamma$-terpinene(20), terpinolene(21), linalool(22), $\alpha$-terpineol(23), nopinone(24) limonene oxide(25), terpinen-4ol(26), methyl chavicol(27), $\beta$-caryophyllene (28). Alternate shaded regions highlight changes in chromatography parameters (for more details, see Table 2).

$\beta$-pinene oxidation product nopinone, within $19.7 \mathrm{~min}$ (giving rise to a $21.8 \mathrm{~min}$ measurement cycle time). Furthermore, these 18 BVOC are sufficiently separated from potentially co-eluting anthropogenic VOC commonly found in urban air, such as the propylbenzene and trimethylbenzene isomers (see Fig. 4). Analytical limitations of this method include partial co-elution of the chromatographic peak pairs corresponding to linalool and $\alpha$-terpineol, $\beta$-pinene and 1,3,5trimethylbenzene, and nopinone and limonene oxide. When present at low to moderate concentrations, each of these partially co-eluting VOC peaks may be individually quantified, albeit with a slightly higher analytical uncertainty compared to other terpenes (see Sect. 2.3). As such, although GC separation of $\mathrm{C}_{9}-\mathrm{C}_{10}$ BVOC sampled from polluted air requires an increased analysis time compared to plant chamber and clean ambient air samples, this Fast-GC system can still offer a moderate improvement in sampling frequency compared to conventional GC methods, as a result of periods of moderately fast chromatography, the reduced post-separation 
cooling time, and a fast temperature ramp rate at the end of each analysis (see Table 2).

It should be noted that quantification of sesquiterpenes in ambient air was not attempted during this study. This was primarily in order to optimise the chromatographic separation of monoterpenes whilst minimising analysis time, but was also due to the presence of co-eluting contaminant peaks introduced via the ozone filters used during ambient air sampling (see Sect. 3.2.1). Furthermore, developing a robust procedure for the accurate quantification of reactive, semivolatile sesquiterpenes in ambient air is analytically challenging (e.g. the $\beta$-caryophyllene lifetime with respect to ozone is $\sim 2 \mathrm{~min}$, Atkinson and Arey, 2003), and was considered beyond the scope of this work.

Figure 3 illustrates the chromatography parameters utilised in the GC_AMBIENT I method (Fig. 3a), and shows typical chromatograms generated using this method for analysis of a monoterpene gas standard (Fig. 3b), and to quantify monoterpenes in ambient air (Fig. 3c). Figure 4 outlines the GC_AMBIENT II method parameters (Fig. 4a), and shows chromatographic traces using this method for analysis of a terpene gas standard (Fig. 4b), and to analyse ambient air within a suburban forest (Fig. 4c). It should be noted that while the GC_AMBIENT II method has already been utilised for continuous in situ terpene monitoring (Fig. 4c - see Sect. 3.2.2 for details), to date the GC_AMBIENT I method has only been used to provide offline analysis of monoterpenes in discrete air samples. As such, the chromatogram presented in Fig. 3c was not produced from an in situ measurement, but from analysis of a whole air sample that was collected within a pine forest in Ibaraki prefecture, Japan. For these measurements, air was sampled into $3 \mathrm{~L}$ silcosteel canisters and subsequently analysed in our laboratory using the GC_AMBIENT I method.

Overall, the Fast-GC methods outlined here facilitate quantification of multiple terpenes in air within a cycle time of $\sim 13.5-22$ min per measurement, which corresponds to a measurement frequency that is $2-5$ times faster than typical conventional GC methods (e.g. Bouvier-Brown et al., 2009; Jones et al., 2011; Hopkins et al., 2011).

\subsection{Fast-GC calibration with respect to terpenes}

One of the major analytical challenges associated with accurate quantification of atmospheric terpenes is the implementation of a robust calibration technique. Compared with other non-methane hydrocarbons (NMHC), monoterpenes often demonstrate inferior stability when stored for prolonged periods in pressurised gas canisters (Apel et al., 1999; Rhoderick and Lin, 2013). Due at least in part to this apparent instability, certified gas standards containing multiple terpenes are not readily available, and hence calibration of these gases is generally less straightforward compared to that of other NMHC. A recent study by Rhoderick and Lin (2013) demonstrates that $20 \mathrm{~L}$ aluminium canisters with proprietary internal coatings are capable of containing gaseous monoterpenes in nitrogen without significant degradation for periods of $>250$ days, however further investigations are necessary to ensure consistency between canisters, and to test whether this level of stability may be achieved for gaseous mixtures containing both $\alpha$-pinene and $\beta$-pinene.

During the initial Fast-GC instrument development phase, calibration with respect to BVOCs was achieved by direct injection of liquid standards via the GC injector port, to derive the FID response factor for each terpene. However, simultaneous measurements of a dynamically diluted $\alpha$-pinene permeation gas by the Fast-GC system and an independently calibrated Agilent GC-FID system (Kato et al., 2004), demonstrated an offset in the derived $\alpha$-pinene mixing ratio, with the Fast-GC measurement consistently $\sim 20 \%$ lower than the GC-FID value. This offset was attributed to a systematic over-estimation of the Fast-GC sample volume (presumably due to unsatisfactory parameterisation of the gas phase sampling conditions). Thus it was apparent that a gas phase calibration procedure was essential in order to achieve accurate terpene quantification (a conclusion that is consistent with other studies, e.g. Apel et al., 1999). Consequently, the calibration procedure for the Fast-GC instrument was modified, and is now based on analysis of a certified primary gas standard containing the monoterpenes $\alpha$-pinene and $\beta$ pinene, in conjunction with the relative FID response factors for the other terpenes (determined by direct injection of BVOC liquid standards).

Gas phase calibration of the Fast-GC with respect to $\alpha$ pinene and $\beta$-pinene is achieved using a 1 ppm 58 component primary VOC gas standard (PAMS-J58, SumitomoSeika Chemicals). VOC tend to exhibit better stability in gaseous mixtures at higher concentrations, however mixing ratios of $1 \mathrm{ppm}$ are too high for use in routine day-today calibrations. Dilution of the primary standard to produce $\sim 5$ ppb VOC mixtures generates effective secondary gas standards suitable for short-term use, however these diluted standards demonstrate significant degradation of the monoterpene components after $\sim 1$ week. As such, independent terpene gas standards are prepared in-house, by injecting $1 \mu \mathrm{L}$ volumes of a liquid standard $\left(\sim 5 \mathrm{mmol} \mathrm{dm}^{-3}\right.$ terpenes in isopropyl alcohol) into a nitrogen gas stream delivered to a $3 \mathrm{~L}$ silcosteel canister, which is subsequently pressurised to $\sim 35$ psi. $100 \mathrm{~mL}$ samples of these "working" terpene gas standards are directly calibrated for $\alpha$-pinene and $\beta$-pinene against small volumes $(10-20 \mathrm{~mL})$ of the $1 \mathrm{ppm}$ PAMS-J58 primary standard, as well as $100 \mathrm{~mL}$ volumes of freshly diluted secondary standards. The mixing ratios of the other components in the terpene gas standard are subsequently derived based upon the ratio of their respective FID responses to the $\alpha$-pinene response factor. Each terpene gas standard typically contains $\sim 1-6 \mathrm{ppb}$ of each terpene component, and is used for the day-to-day calibration of the FastGC instrument. 
The relative response of the FID to each monoterpene, oxygenated terpenoid and sesquiterpene was determined by direct injection of 5 liquid standards containing all target BVOC in the concentration range $3 \mu \mathrm{mol} \mathrm{dm}{ }^{-3}-$ $3 \mathrm{mmol} \mathrm{dm}^{-3}$. The solutions were prepared volumetrically, by sequential dilution of pure BVOC liquids (Aldrich and Wako, all > 97-99\% purity) in dichloromethane solvent. Direct injection of $0.2 \mu \mathrm{L}$ volumes of each liquid standard was used to derive the FID response for each species. The response factors for the individual monoterpenes were comparable (all within $\sim 15 \%$ of the $\alpha$-pinene response), with the exception of myrcene, which produced an FID response $\sim 25 \%$ lower than that of $\alpha$-pinene. It is notable that a similar myrcene/ $\alpha$-pinene relative FID response ratio was observed by Faiola et al. (2012). It should also be noted that since the monoterpene camphene is solid at room temperature, in this case the FID response was assumed to be equivalent to that of $\beta$-pinene.

In general, a new working terpene gas standard is prepared immediately prior to a field measurement campaign or series of plant chamber experiments, and is subsequently used for day-to-day calibration of the Fast-GC for the duration of that study (typically 2-6 weeks). Stability tests indicate that the monoterpenes are comparatively stable within these low pressure terpene gas mixtures for a period of $\sim 10$ weeks. Periodic analysis of a single terpene gas standard (twice a week over a 10 week period) revealed a $1 \sigma$ variation in peak area of $\pm 5-10 \%$ for monoterpenes, with no statistically significant overall reduction in concentration outside of this uncertainty. The oxygenated terpenes exhibited a larger degree of variability, with peak areas varying by $\pm 12-25 \%$. Although some OBVOC, such as methyl chavicol, did not undergo significant degradation over this period, other species (notably linalool and nopinone) demonstrated an overall loss of $\sim 20 \%$ after 6 weeks, and as much as $\sim 40 \%$ degradation after 10 weeks. As such, the OBVOC in the working terpene standard were used for peak identification purposes only, and quantification was based on the relative FID response to $\alpha$-pinene. Faiola et al. (2012) demonstrate that the widely used effective carbon number (ECN) approximation of relative FID response is a valid approach for quantification of naturally occurring terpenes. Their results suggest that FID calibration for monoterpenes using the theoretical ECN and relative molar response approximation can achieve effective quantification within a $10 \%$ measurement uncertainty.

For simplicity, $\beta$-caryophyllene was the only sesquiterpene included in the terpene standard, and showed a variation of $\pm 14 \%$ over a 10 week period, but no statistically significant degradation. It should be noted that other factors may contribute to the observed variations in terpene mixing ratios within the gas standard, such as small changes in instrument sensitivity.

The $2 \sigma$ limits of detection (LOD) for each terpene quantified via the Fast-GC methods outlined here are given in Table 1. The overall uncertainties in Fast-GC quantification using these methods are $\pm 8-12 \%$ for monoterpenes, $\pm 14-$ $26 \%$ for OBVOC and $\pm 15-20 \%$ for sesquiterpenes. Where chromatographic peaks are not fully baseline resolved, the corresponding BVOC are subject to the higher uncertainties (e.g. $\pm \sim 11-12 \%$ for $\Delta$-3-carene and $\alpha$-terpinene in plant chamber studies, and $\pm 12 \%$ for $\beta$-pinene in ambient air). The greater uncertainty associated with quantification of OBVOC and sesquiterpenes in comparison with monoterpenes is primarily due to reduced precision (presumably as a result of wall losses and/or memory effects, which are characteristic of the less volatile and/or more polar terpenes). It should be noted that this dual gas and liquid standard calibration results in slightly higher measurement uncertainties for terpenes calibrated based upon their relative FID response (in order to account for errors in the liquid calibration procedure), however, in the absence of a reliable commercially available primary gas standard containing all terpenes of interest, this method offers an effective, practical alternative calibration procedure.

\subsection{PTR-MS instrument details}

A Proton Transfer Reaction - Quadrupole Mass Spectrometer (PTR-MS, Ionicon Analytik, Austria) was operated alongside the Fast-GC to provide a direct comparison of monoterpene quantification during various applications (see Sect. 3). The total monoterpene mixing ratio was determined by PTRMS during plant chamber studies and ambient air monitoring, based on the sum of the $m / z 81$ and $m / z 137$ signals (with a dwell time of $1 \mathrm{~s}$ ). The PTR-MS was independently calibrated for monterpenes via an $\alpha$-pinene permeation tube system and cross-calibration with a conventional GC-FID instrument (Agilent 6890). Drift tube conditions were $500 \mathrm{~V}$, $45^{\circ} \mathrm{C}$ and 1.97 mbar, giving rise to an $\mathrm{E} / \mathrm{N}$ ratio of $117 \mathrm{Td}$. Air was sampled at a rate of $50 \mathrm{~mL} \mathrm{~min}^{-1}$, and the instrument was supplied with zero air (model 111 Zero Air Supply, Thermo Scientific) for the first 15 min of every hour, and analysed sample air for the subsequent $45 \mathrm{~min}$. The zero signal measured directly before and after each 45 min measurement period was averaged and subtracted from the intermediate ambient data. Under these operating conditions, the $2 \sigma$ limit of detection for total monoterpene mixing ratio determined by PTR-MS was $\sim 60 \mathrm{ppt}$, with an associated measurement uncertainty of $\sim 16 \%$, for 1 min averaged data.

\section{Applications for Fast-GC quantification of terpenes in air}

This section provides a brief outline of two practical applications of Fast-GC quantification of terpenes in air using the methods detailed in Sect. 2 - namely plant chamber experiments and ambient air monitoring. It should be noted that more in-depth discussions of each of these studies will be presented elsewhere. 


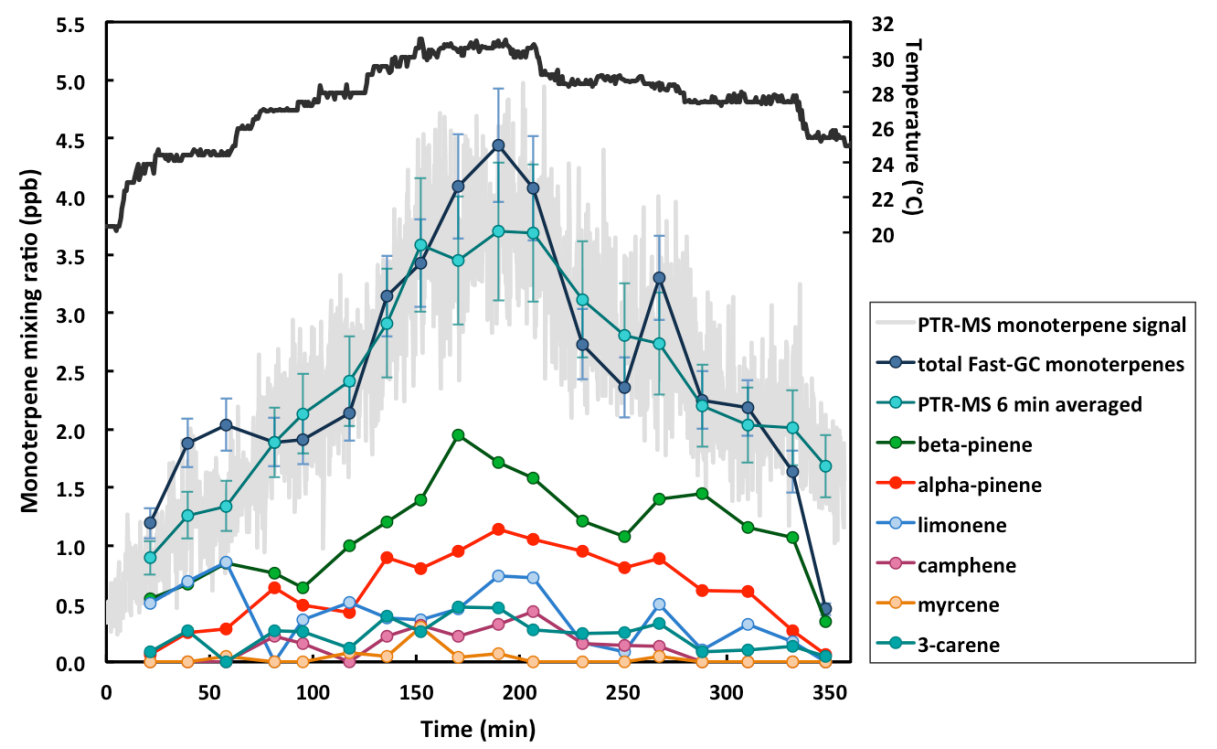

Fig. 5. Monoterpenes in white spruce emissions, as determined by Fast-GC during a plant chamber study. The GC_CHAMBER chromatography method was used to determine the monoterpene composition, at a sample frequency of 1 measurement every $\sim 17$ min. The sum of the individual monoterpenes measured by Fast-GC is overlaid with the simultaneously measured $15 \mathrm{~s}$ PTR-MS total monoterpene signal, and the PTR-MS signal averaged over each 6-min Fast-GC sampling period.

\subsection{Plant chamber studies}

The Fast-GC instrument has been utilised to monitor the terpene composition of white spruce (Picea glauca) emissions during single plant chamber studies. During these experiments, a young white spruce plant $(\sim 50 \mathrm{~cm}$ tall $)$ potted in soil was enclosed in a $\sim 5 \mathrm{~L}$ teflon chamber and supplied with $\sim 3 \mathrm{~L} \mathrm{~min}^{-1}$ continuous flow of dry air (including ambient $\mathrm{CO}_{2}$ levels) from a zero air generator (Model 111, Thermo Scientific). The humidity of the chamber air was not controlled, and as such it gradually increased during the course of the experiment, as a result of transpiration. The outflow from the chamber was diverted from a common sample line for simultaneous sub-sampling by Fast-GC (using the dedicated GC_CHAMBER chromatography method outlined in Sect. 2.2.1), PTR-MS, and a Laser Induced Fluorescence (LIF) instrument for $\mathrm{OH}$ reactivity measurements (Nakashima et al., 2014). The temperature and irradiance of the chamber were controlled such that emissions could be analysed under a range of different simulated environmental conditions. Prior to each experiment, plants were maintained within a dedicated greenhouse facility operated by the $\mathrm{Na}$ tional Institute for Environmental Studies (NIES).

Figure 5 shows the mixing ratios of the monoterpenes $\alpha$-pinene, $\beta$-pinene, limonene, camphene, myrcene and $\Delta$ 3 -carene in white spruce emissions quantified by Fast-GC. During this experiment, the monoterpene mixing ratios were monitored continuously for a $\sim 6 \mathrm{~h}$ period with an average sampling frequency of one $6 \mathrm{~min}$ averaged measurement every $\sim 17 \mathrm{~min}$, while the chamber was exposed to constant light conditions $\left(\sim 900 \mu \mathrm{mol} \mathrm{m}^{-2} \mathrm{~s}^{-1}\right)$ and a variable temperature $\left(23-31^{\circ} \mathrm{C}\right)$. The individual monoterpene mixing ratios ranged from $\sim 10 \mathrm{ppt}-1.9 \mathrm{ppb}$, with the higher concentrations coinciding with the higher chamber temperatures. Figure 5 also illustrates the good agreement between the sum of the individual monoterpenes quantified by Fast-GC and the PTR-MS total monoterpene signal. It should be noted that measurements at the start and end of the experiment correspond to the lowest chamber temperatures $\left(<25^{\circ} \mathrm{C}\right)$ and therefore minimum monoterpene mixing ratios. As a result, some of the individual monoterpenes quantified by Fast-GC were close to (or below) the instrument detection limit at these times, and the agreement between Fast-GC and PTR-MS derived monoterpene mixing ratios was reduced in comparison with data from other periods. The correlation between the Fast-GC and PTR-MS derived total monoterpene mixing ratios measured during this experiment is presented in Fig. 7. It should be noted that the final Fast-GC measurement was classed as an outlier (since all but one of the individual monoterpenes were below the instrument detection limit) and was thus excluded from this plot. Figure 7 demonstrates the close agreement between the two instruments for quantification of monoterpenes in single plant emission studies $\left(R^{2}\right.$ coefficient $\left.=0.82\right)$, and indicates that the total monoterpene mixing ratio reported by Fast-GC was on average $\sim 4 \%$ higher than the corresponding PTR-MS value. As such, the total monoterpene mixing ratios reported by the two instruments may be considered equivalent, within the experimental uncertainties. 


\subsection{Ambient air monitoring}

The Fast-GC analytical system used throughout this study is smaller, lighter (and hence more portable) and operates with reduced power consumption $(<1 \mathrm{~kW})$ compared to most conventional GC instruments, primarily since it does not contain a large GC oven (see Sect. 2.2). As such, this instrument is ideally suited to short-term in-situ ambient air monitoring of VOC in the field.

\subsubsection{Ozone removal}

Terpenes pre-concentrated from ambient air are susceptible to significant oxidant-mediated destruction within the sample lines and sorbent trap, as a result of their short atmospheric lifetimes with respect to ozone (Helmig, 1997 and references therein). Therefore, when monitoring terpenes in moderate to high ozone environments, it is desirable to incorporate an integrated ozone scrubber within the sampling system. Ozone-mediated destruction of monoterpenes within the Fast-GC sampling system (see Sect. 2.1) was assessed using $\sim 2$ ppb $\alpha$-pinene in dry air, supplied via a permeation oven. In the presence of $\sim 50 \mathrm{ppb}$ ozone, the $\alpha$-pinene peak area was reduced by $\sim 6 \pm 2 \%$ compared to samples without ozone. Furthermore, a new unidentified chromatographic peak was observed when sampling $\alpha$-pinene in the presence of ozone. This unidentified peak was eluted in the retention window corresponding to $\mathrm{C}_{9}-\mathrm{C}_{10}$ oxygenated terpenes, which suggests that it may be an $\alpha$-pinene oxidation product. Consequently, when conducting ambient air terpene measurements, a $25 \mathrm{~mm}$ sodium thiosulfate $\left(\mathrm{Na}_{2} \mathrm{~S}_{2} \mathrm{O}_{3}\right)$ impregnated Acrodisc glass fibre filter $(1 \mu \mathrm{m}$ pore size $)$ is installed between the main sampling manifold and Fast-GC sample line, in order to minimise oxidant interferences (for details regarding filter preparation and suitability for treating gaseous terpene samples, see Pollmann et al., 2005). The ozone removal efficiency of these filters was tested in situ, using a commercial ozone analyser (model 49C, Thermo Scientific). With the $\mathrm{Na}_{2} \mathrm{~S}_{2} \mathrm{O}_{3}$ filter inline, ambient ozone mixing ratios of $\sim 60-80 \mathrm{ppb}$ were effectively reduced to around $0.5-1.5 \mathrm{ppb}$. The filter was routinely changed after 5 days continuous sampling, however the used filters showed no reduction in ozone removal efficiency relative to the un-used filters. Helmig (1997) reported that the capacity of these filters may be $>1 \mathrm{~m}^{3}$ air for ambient ozone levels, which, based on our sample volume and frequency, should theoretically allow continuous use for more than 2 weeks.

Tests to assess terpene losses to the $\mathrm{Na}_{2} \mathrm{~S}_{2} \mathrm{O}_{3}$ filter surface were performed using an in-house prepared gaseous mixture containing $\sim 0.5-1.5 \mathrm{ppb}$ monoterpenes and selected oxygenated $\mathrm{C}_{10}$ terpenes in nitrogen (for details see Sect. 2.3). The terpene gas standard was sampled with and without a $\mathrm{Na}_{2} \mathrm{~S}_{2} \mathrm{O}_{3}$ filter inline, and average losses of $\sim 3 \pm 2 \%$ for monoterpenes and $\sim 5 \pm 2 \%$ for oxygenated terpenoids were observed when sampling via a filter. Of the monoterpenes, the largest percentage loss was observed for $\Delta$-3-carene $(4.9 \%)$, while the limonene mixing ratio demonstrated the smallest decrease $(0.7 \%)$ when sampling via the filter. Ambient air observations are corrected to account for these relatively small losses, which are within the measurement uncertainty.

\subsubsection{Ambient terpene measurements in a suburban forest}

Our Fast-GC system was deployed to provide continuous automated measurements of monoterpenes and $\mathrm{C}_{10}$ OBVOC in boundary layer air at a suburban forest site within the Tokyo metropolis, for 10 days during September and October 2012. Ambient air monitoring was performed at the Field Museum Tama (FM Tama) measurement station $\left(35^{\circ} 38^{\prime} \mathrm{N}\right.$, $139^{\circ} 22^{\prime} \mathrm{E}$ ), which is operated by Tokyo University of Agriculture and Technology, as part of the AQUAS TAMA (Air Quality Study at FM Tama) 2012 field campaign. The site is located in a small forest $\sim 30 \mathrm{~km}$ west of central Tokyo, where the dominant tree species are Cryptomeria japonica (Japanese cedar), Chamaecyparis obtusa (Japanese cypress) and Quercus serrata (an indigenous Japanese oak). Throughout the 10 day continuous monitoring period, the site experienced temperatures in the range $\sim 17-29^{\circ} \mathrm{C}$, and wind speeds of $\sim 1-5 \mathrm{~m} \mathrm{~s}^{-1}$ (increasing to $\sim 20 \mathrm{~m} \mathrm{~s}^{-1}$ during a typhoon from 30 September-1 October). To our knowledge, this study represents the first in situ Fast-GC observations of terpenes in ambient air.

Figure 6 shows the time series resulting from continuous Fast-GC observations of 6 monoterpenes and linalool in ambient air at FM Tama, from 24 September to 4 October 2012. As the site was subjected to some local pollution, the GC_AMBIENT II method was utilised for these observations, which resulted in a Fast-GC sampling frequency of 1 sample every $\sim 22 \mathrm{~min}$. Air was drawn from an inlet on the roof of the two storey measurement station via an $8 \mathrm{~m}$ $\left(1 / 2^{\prime \prime}\right.$ i.d.) PFA manifold at a rate of $\sim 5 \mathrm{~L} \mathrm{~min}^{-1}$, and subsampled from this manifold through a $\mathrm{Na}_{2} \mathrm{~S}_{2} \mathrm{O}_{3}$ ozone filter and $\sim 1 \mathrm{~m} \times 1 / 800 \mathrm{PFA}$ line at $75 \mathrm{~mL} \mathrm{~min}^{-1}$ to the Unity 2 thermal desorber/Fast-GC system (see Fig. 1). The $\mathrm{Na}_{2} \mathrm{~S}_{2} \mathrm{O}_{3}$ filter was positioned within the sub-sample line rather than at the inlet, since the main manifold also supplied air to several other instruments, some of which required ozone to be present in the air supply. However, the relatively high flow rate through the main manifold resulted in a residence time of $<30 \mathrm{~s}$, and as such significant ozone destruction was not anticipated within this sample line. Furthermore, given the high flow rate through the main manifold and the limited capacity of the $\mathrm{Na}_{2} \mathrm{~S}_{2} \mathrm{O}_{3}$ filters, positioning the filter at the inlet would have necessitated a filter change every few hours.

Biogenic emissions at this site were dominated by isoprene, whilst monoterpenes were detected at comparatively lower concentrations. The monoterpene composition was dominated by $\alpha$-pinene, $\beta$-pinene and $\Delta 3$-carene, whilst 

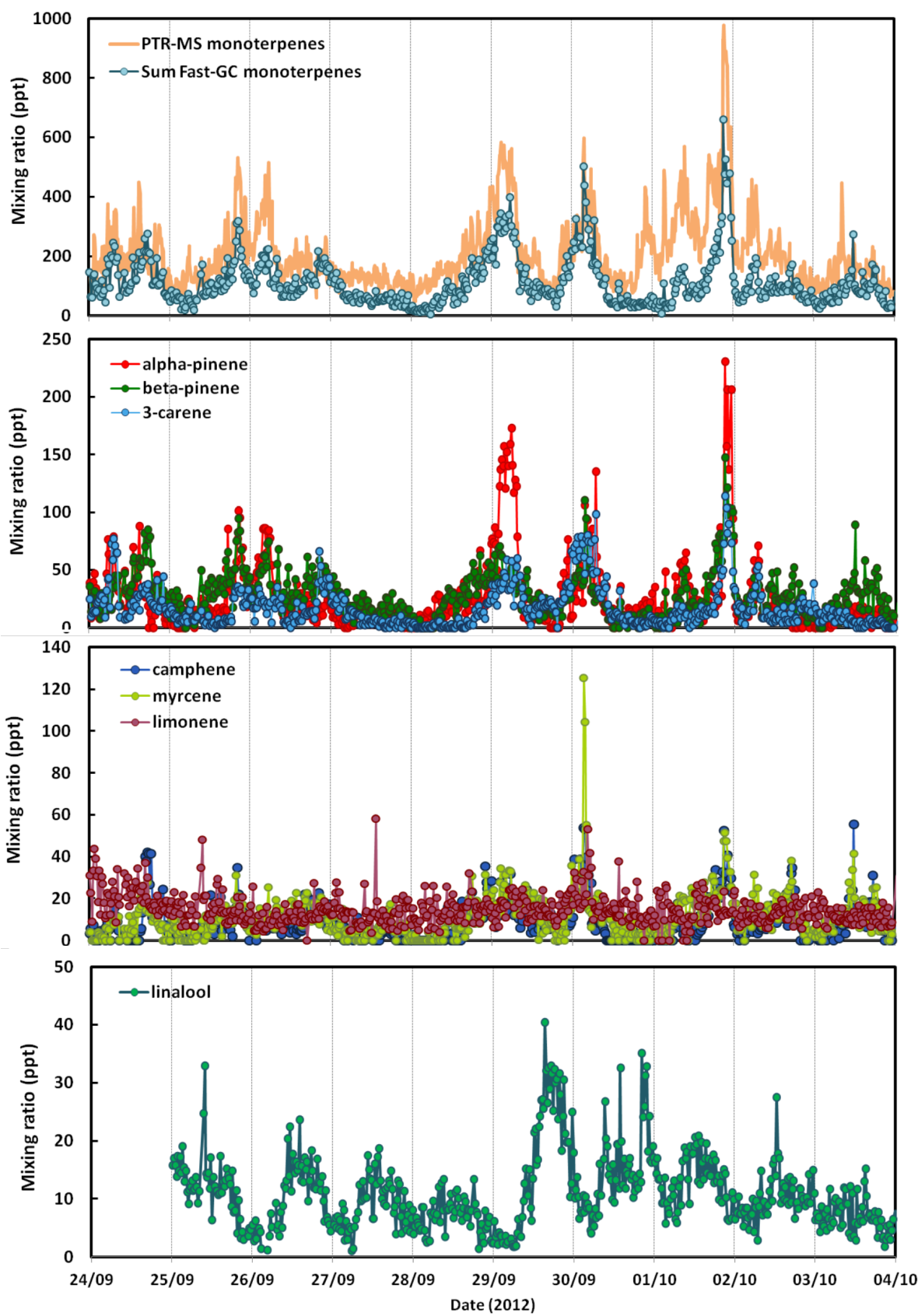

Fig. 6. Time series showing the sum of Fast-GC quantified monoterpenes and $10 \mathrm{~min}$ averaged PTR-MS monoterpene signal, as well as mixing ratios of selected individual terpenes monitored by Fast-GC at the FM Tama field station in the Tokyo metropolis, during SeptemberOctober 2012. Fast-GC analyses were performed using GC_AMBIENT II method, resulting in a sample frequency of 1 measurement every $\sim 22$ min. The Fast-GC instrumental uncertainties were $8-12 \%$ for monoterpenes, and $20 \%$ for linalool.

mixing ratios of limonene, myrcene and camphene were generally lower, and often close to the instrument detection limit. The highest monoterpene mixing ratios were typically observed at night, presumably since temperatures remained high enough to drive emissions, whilst oxidant levels decreased relative to daytime, and contraction of the boundary layer reduced vertical dilution of local emissions.
Similar monoterpene diurnal profiles have also been reported at other sites (Bouvier-Brown et al., 2009; Nakashima et al., 2014). In contrast, the maximum linalool mixing ratio at FM Tama was observed during early afternoon, while night time concentrations were often close to the instrument detection limit (4 ppt), giving rise to a diurnal profile characteristic of 


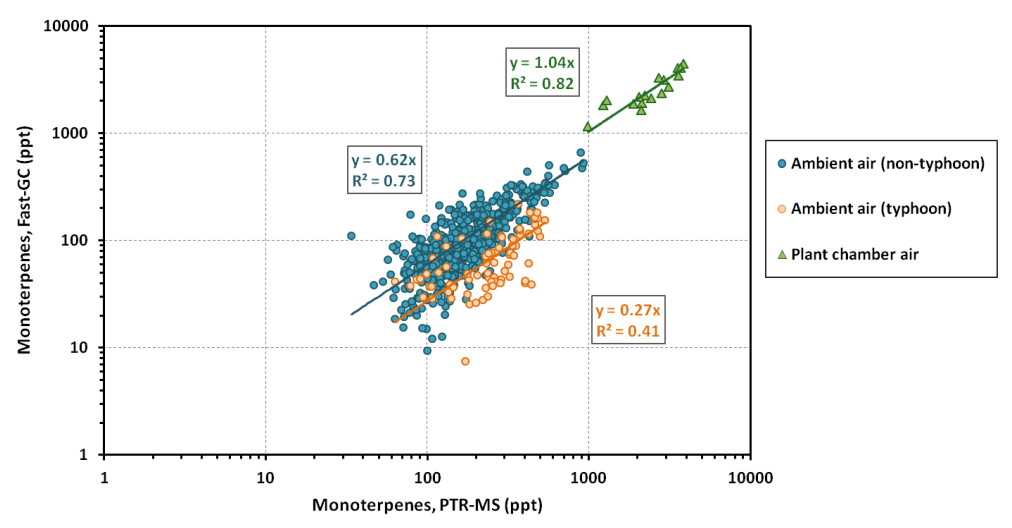

Fig. 7. Correlation plots of Fast-GC vs. PTR-MS derived total monoterpene mixing ratios, based on simultaneous measurements during ambient air observations (see Sect. 3.2.2) and plant chamber measurements (see Sect. 3.1). In each case, PTR-MS values are averaged over the relevant Fast-GC sampling period.

primary BVOC with a light and temperature dependent emission rate.

The sum of the individual monoterpenes quantified by Fast-GC was in reasonable agreement with the total monoterpene mixing ratio measured by a co-located PTR-MS (see Fig. 6), although the Fast-GC value was consistently lower. Figure 7 shows correlation plots for PTR-MS vs. Fast-GC derived monoterpene mixing ratios during the AQUAS TAMA campaign (using PTR-MS values averaged over each 10 min Fast-GC sampling period). Data recorded during the typhoon event (classified according to in situ atmospheric pressure measurements at the FM Tama field station) were analysed separately; for these purposes, measurements corresponding to atmospheric pressures of $965-985 \mathrm{hPa}$ were classed as "typhoon" observations. Excluding the typhoon data, Fig. 7 demonstrates a good correlation between the PTR-MS and Fast-GC monoterpene measurements $\left(R^{2}\right.$ coefficient $=0.73$ ), however the slope indicates that the FastGC value was on average $38 \%$ lower than the corresponding PTR-MS value. This is a significant offset, and is outside of instrumental uncertainties (10\% for the total monoterpene mixing ratio quantified by Fast-GC, and $16 \%$ for PTRMS). A similar offset was reported in the monoterpene fluxes derived by conventional GC-MS and PTR-MS instruments above a Californian ponderosa pine plantation (Lee et al., 2005), and indicates the presence of additional monoterpenes below the GC detection limit, and/or some interference from other compounds to the PTR-MS signal $(\mathrm{m} / \mathrm{z} 81$ and 137), although other explanations, such as inaccuracies in the zero air subtraction for the PTR-MS signal or systematic discrepancies resulting from the use of different calibration techniques, should also be considered. Several other studies have also reported offsets between PTR-MS and GC derived ambient monoterpene mixing ratios, with GC instruments typically reporting lower monoterpene concentrations compared to PTR-MS, by $\sim 20-50 \%$ (de Gouw and Warnecke, 2007). The average offset between the PTR-MS and
Fast-GC derived monoterpene mixing ratios at the FM Tama field station increased from $\sim 38 \%$ to $\sim 73 \%$ when the site was subjected to a typhoon weather system, from 30 September to 1 October (see Fig. 7). The correlation between two instruments was also relatively poor under typhoon conditions $\left(R^{2}\right.$ coefficient $\left.=0.41\right)$, however the reason for the larger discrepancy during this period has not yet been identified.

\section{Discussion and summary}

We have developed a novel Fast-GC based approach for targeted analysis of a range of $\mathrm{C}_{9}-\mathrm{C}_{15}$ BVOC in air, with flame ionisation detection. The three methods outlined in this study retain the chromatographic separation capability of conventional GC (to provide quantification of individual terpene isomers), whilst offering improved sampling frequency to facilitate effective monitoring of short-term variations in the terpene composition of single plant emissions and ambient air.

We demonstrate that the terpene composition of pristine forest air (with minimal anthropogenic influence) and single plant emissions may be effectively analysed by moderately fast GC methods, with measurement frequencies of one sample every 13.7 and $16.5 \mathrm{~min}$, respectively (see Table 2 for details). However, in light of recent studies reporting significant BVOC mediated ozone formation within the urban boundary layer (Lee et al., 2006; Curci et al., 2009), there is increasing motivation for in situ observations of these biogenic gases in polluted atmospheres, as well as within clean forest air. As such, we have also developed a Fast-GC based method suitable for the quantification of monoterpenes and selected OBVOC in polluted environments, where significant concentrations of anthropogenic VOC and BVOC are present. Initial tests demonstrated that analysis of these more complex VOC compositions is not a viable application for very fast GC, and in order to avoid substantial peak co-elution it is necessary to use a combination of moderately fast gas chromatography 
in conjunction with periods of more conventional (and in some cases isothermal) separation. Under these conditions, the measurement cycle time is increased to $21.8 \mathrm{~min}$.

Overall, the chromatography methods outlined in this study offer a procedure for comprehensive analysis of speciated monoterpenes, selected oxygenated terpenoids including the $\beta$-pinene oxidation product nopinone, and (in plant chamber studies) sesquiterpenes, with a measurement frequency 2-5 times higher than conventional GC methods. We have successfully applied these Fast-GC methods to provide terpene composition analysis of single plant emissions and ambient air. Throughout the plant chamber studies, the sum of the Fast-GC derived monoterpene mixing ratios was generally in good agreement with the total monoterpene mixing ratio derived from simultaneous PTR-MS measurements (within $4 \%$ ). In contrast, during in situ ambient air observations, the Fast-GC and PTR-MS derived monoterpene mixing ratios demonstrated an average offset of $38 \%$. Such an offset has also been reported in previous studies comparing GC and PTR-MS ambient monoterpene measurements (e.g. Lee et al., 2005; de Gouw and Warneke, 2007), suggesting that this is a commonly observed instrumental inconsistency which requires further investigation by the atmospheric monoterpene measurement community.

Due to the vast number of naturally occurring BVOC, co-elution of two or more species must be considered as a potential limitation of Fast-GC-FID terpene analysis. Other techniques with superior separation capability, such as two dimensional gas chromatography (2-D GC), offer improved chromatographic resolution but have other limitations, such as relatively poor time resolution, lack of portability (making 2D GC unsuitable for short-term field deployments), and requiring a large amount of data processing (hence 2-D GC is not an appropriate technique for long-term in situ monitoring). In this regard, the most suitable technique should be selected for each specific application. For applications where the main objective is high time resolution quantification of speciated monoterpenes, Fast-GC may arguably be the most suitable technique, whereas for quantification of very complex mixtures containing multiple OBVOCs (and where high time resolution is not required), a 2-D GC technique may be more appropriate.

In future, the Fast-GC methods presented in this study could potentially be utilised for indirect monoterpene flux measurements, in conjunction with techniques such as relaxed eddy accumulation (REA). The shorter measurement cycles offered by Fast-GC would be particularly advantageous in this application, where measurement frequency is often limited by sample analysis time, and there may be concerns related to sample degradation in the interval between sampling and analysis.

Recent developments in analytical methodologies have advanced the ambient air terpene monitoring capabilities of both GC (e.g. this study; Purvis et al., 2013) and PTRMS (e.g. Misztal et al., 2012) based techniques, as well as offline sampling methods (e.g. Yassaa et al., 2010). However, even these state-of-the-art techniques still focus primarily on isoprene and/or monoterpenes, while the number of ambient sesquiterpene and oxygenated terpene observations remain comparatively limited. Moreover, $\mathrm{OH}$ reactivity measurements suggest that the fraction of unidentified reactive BVOC in ambient air remains significant. As such, further instrumental developments to increase the chemical diversity and spatiotemporal resolution of terpene observations are fundamental to obtaining a more in-depth understanding of the role of these gases in atmospheric processes that influence air quality and climate.

Acknowledgements. The authors thank Kazuhide Matsuda from the FM Tama field station (Tokyo University of Agriculture and Technology). This research was partially supported by a Japan Society for the Promotion of Science short-term international fellowship (award no. PE10569), a Grant-in-Aid for Scientific Research (S) 21221001 from the Ministry of Education, Culture, Science, Sports, and Technology, Japan, and an Environment Research and Technology Development Fund (5-1301) provided by the Ministry of the Environment, Government of Japan.

Edited by: D. Heard

\section{References}

Andreae, M. O. and Crutzen, P. J.: Atmospheric Aerosols: Biogeochemical Sources and Role in Atmospheric Chemistry, Science, 276, 1052-1058, 1997.

Apel, E. C., Calvert, J. G., Gilpin, T. M., Fehsenfeld, F. C., Parrish, D. D., and Lonneman, W. A.: The Nonmethane Hydrocarbon Intercomparison Experiment (NOMHICE) - Task 3, J. Geophys. Res., 104, 26069-26086, 1999.

Apel, E. C., Hills, A. J., Lueb, R., Zindel, S., Eisele, S., and Riemer, D. D.: A fast-GC/MS system to measure $C_{2}$ to $C_{4}$ carbonyls and methanol aboard aircraft, J. Geophys. Res.-Atmos., 108, 8794, doi:10.1029/2002JD003199, 2003.

Atkinson, R.: Gas-phase tropospheric chemistry of volatile organic compounds: 1. Alkanes and alkenes, Phys. Chem. Ref. Data, 26, 215-290, 1997.

Atkinson, R. and Arey, J.: Atmospheric Degradation of Volatile Organic Compounds, Chem. Rev., 103, 4605-4638, doi:10.1021/cr0206420, 2003.

Atkinson, R., Hasegawa, D., and Aschmann, S. M.: Rate constants for the gas-phase reactions of $\mathrm{O}_{3}$ with a series of monoterpenes and related compounds at $296 \pm 2 \mathrm{~K}$, Int. J. Chem. Kinet., 22, 871-887, 1990.

Atkinson, R., Arey, J., Aschmann, S. M., Corchnoy, S. B., and Shu, Y.: Rate Constants for the Gas-Phase Reactions of cis-3Hexen-1-ol, is-3-Hexenylacetate, trans-2-Hexenal, and Linalool with $\mathrm{OH}$ and $\mathrm{NO}_{3}$ Radicals and $\mathrm{O}_{3}$ at $296 \pm 2 \mathrm{~K}$, and $\mathrm{OH}$ Radical Formation Yields from the $\mathrm{O}_{3}$ Reactions, Int. J. Chem. Kinet., 27, 941-955, 1995. 
Bouvier-Brown, N. C., Goldstein, A. H., Gilman, J. B., Kuster, W. C., and de Gouw, J. A.: In-situ ambient quantification of monoterpenes, sesquiterpenes, and related oxygenated compounds during BEARPEX 2007: implications for gas- and particle-phase chemistry, Atmos. Chem. Phys., 9, 5505-5518, doi:10.5194/acp-9-5505-2009, 2009.

Calogirou, A., Jensen, N. R., Nielsen, C. J., Kotzias, D., and Hjorth, J.: Gas-Phase Reactions of Nopinone, 3-Isopropenyl6-oxo-heptanal, and 5-Methyl-5-vinyltetrahydrofuran-2-ol with $\mathrm{OH}, \mathrm{NO}_{3}$, and Ozone, Environ. Sci. Technol., 33, 453-460, 1999.

Chameides, W. L., Lindsay, R. W., Richardson, J., and Klang, C. S.: The Role of Biogenic Hydrocarbons in Urban Photochemical Smog: Atlanta as a Case Study, Science, 241, 1473-1474, 1988.

Corchnoy, S. B. and Atkinson, R.: Kinetics of the Gas-Phase Reactions of $\mathrm{OH}$ and $\mathrm{NO}_{3}$ Radicals with 2-Carene, 1,8-Cineole, p-Cymene, and Terpinolene, Environ. Sci. Technol., 24, 14971502, 1990.

Curci, G., Beekmann, M., Vautard, R., Smiatek, G., Steinbrecher, R., Theloke, J., and Friedrich, R.: Modelling study of the impact of isoprene and terpene biogenic emissions on European ozone levels, Atmos. Environ., 43, 1444-1455, 2009.

de Gouw, J. and Warneke, C.: Measurements of volatile organic compounds in the earth's atmosphere using proton-transferreaction mass spectrometry, Mass Spectrom. Rev., 26, 223-257, 2007.

Di Carlo, P., Brune, W. H., Martinez, M., Harder, H., Lesher, R., Ren, X., Thornberry, T., Carroll, M. A., Young, V., Shepson, P. B., Riemer, D., Apel, E., and Campbell, C.: Missing OH Reactivity in a Forest: Evidence for Unknown Reactive Biogenic VOCs, Science, 304, 722-725, doi:10.1126/science.1094392, 2004.

Eckenrode, B. A.: Environmental and forensic applications of fieldportable GCMS: An overview, J. Am. Soc. Mass Spectrom., 12, 683-693, 2001.

Edwards, P. M., Evans, M. J., Furneaux, K. L., Hopkins, J., Ingham, T., Jones, C., Lee, J. D., Lewis, A. C., Moller, S. J., Stone, D., Whalley, L. K., and Heard, D. E.: OH reactivity in a South East Asian tropical rainforest during the Oxidant and Particle Photochemical Processes (OP3) project, Atmos. Chem. Phys., 13, 9497-9514, doi:10.5194/acp-13-9497-2013, 2013.

Faiola, C. L., Erickson, M. H., Fricaud, V. L., Jobson, B. T., and VanReken, T. M.: Quantification of biogenic volatile organic compounds with a flame ionization detector using the effective carbon number concept, Atmos. Meas. Tech., 5, 1911-1923, doi:10.5194/amt-5-1911-2012, 2012.

Fuentes, J. D., Lerdau, M., Atkinson, R., Baldocchi, D., Bottenheim, J. W., Ciccioli, P., Lamb, B., Geron, C., Gu, L., Guenther, A., Sharkey, T. D., and Stockwell, W.: Biogenic hydrocarbons in the atmospheric boundary layer: A review, B. Am. Meteorol. Soc., 81, 1537-1575, 2000.

Greenberg, J. P., Guenther, A., Zimmerman, P., Baugh, W., Geron, C., Davis, K., Helmig, D., and Klinger, L. F.: Tethered balloon measurements of biogenic VOCs in the atmospheric boundary layer, Atmos. Environ., 33, 855-867, 1999.

Guenther, A., Hewitt, C. N., Erickson, D., Fall, R., Geron, C., Graedel, T., Harley, P., Klinger, L., Lerdau, M., McKay, W. A., Pierce, T., Scholes, B., Steinbrecher, R., Tallamraju, R., Taylor, J., and Zimmerman, P.: A global model of natural volatile organic compound emissions, J. Geophys. Res., 100, 8873-8892, 1995.
Hamilton, J. F. and Lewis, A. C.: Monoaromatic complexity in urban air and gasoline assessed using comprehensive GC and fast GC-TOF/MS, Atmos. Environ., 37, 589-602, 2003.

Helmig, D.: Ozone removal techniques in the sampling of atmospheric volatile organic trace gases, Atmos. Environ., 31, 36353651, 1997.

Holzinger, R., Lee, A., Paw, K. T., and Goldstein, U. A. H.: Observations of oxidation products above a forest imply biogenic emissions of very reactive compounds, Atmos. Chem. Phys., 5, 67-75, doi:10.5194/acp-5-67-2005, 2005.

Holzke, C., Dindorf, T., Kesselmeier, J., Kuhn, U., and Koppmann, R.: Terpene emissions from European beech (Fagus sylvatica L.): Pattern and emission behaviour over two vegetation periods, J. Atmos. Chem., 55, 81-102, doi:10.1007/s10874-006-9027-9, 2006.

Hopkins, J. R., Jones, C. E., Lewis, A. C.: A dual channel gas chromatograph for atmospheric analysis of volatile organic compounds including oxygenated and monoterpene compounds, J. Environ. Monit., 13, 2268-2276, 2011.

Jones, C. E., Hopkins, J. R., and Lewis, A. C.: In situ measurements of isoprene and monoterpenes within a south-east Asian tropical rainforest, Atmos. Chem. Phys., 11, 6971-6984, doi:10.5194/acp-11-6971-2011, 2011.

Kato, S., Miyakawa, Y., Kaneko, T., and Kajii, Y.: Urban air measurements using PTR-MS in Tokyo area and comparison with GC-FID measurements, Int. J. Mass Spectrom., 235, 103-110, 2004.

Kesselmeier, J. and Staudt, M.: Biogenic Volatile Organic Compounds (VOC): An Overview on Emission, Physiology and Ecology, J. Atmos. Chem., 33, 23-88, 1999.

Langford, B., Misztal, P. K., Nemitz, E., Davison, B., Helfter, C., Pugh, T. A. M., MacKenzie, A. R., Lim, S. F., and Hewitt, C. N.: Fluxes and concentrations of volatile organic compounds from a South-East Asian tropical rainforest, Atmos. Chem. Phys., 10, 8391-8412, doi:10.5194/acp-10-8391-2010, 2010.

Lee, A., Schade, G. W., Holzinger, R., and Goldstein, A. H.: A comparison of new measurements of total monoterpene flux with improved measurements of speciated monoterpene flux, Atmos. Chem. Phys., 5, 505-513, doi:10.5194/acp-5-505-2005, 2005.

Lee, J. D., Lewis, A. C., Monks, P. S., Jacob, M., Hamilton, J. F., Hopkins, J. R., Watson, N. M., Saxton, J. E., Ennis, C., Carpenter, L. J., Carslaw, N., Fleming, Z., Bandy, B. J., Oram, D. E., Penkett, S. A., Slemr, J., Norton, E., Rickard, A. R., Whalley, L. K., Heard, D. E., Bloss, W. J., Gravestock, T., Smith, S. C., Stanton, J., Pilling, M. J., and Jenkin, M.E.; Ozone photochemistry and elevated isoprene during the UK heatwave of august 2003, Atmos. Environ., 40, 7598-7613, 2006.

Lou, S., Holland, F., Rohrer, F., Lu, K., Bohn, B., Brauers, T., Chang, C. C., Fuchs, H., Häseler, R., Kita, K., Kondo, Y., Li, X., Shao, M., Zeng, L., Wahner, A., Zhang, Y., Wang, W., and Hofzumahaus, A.: Atmospheric $\mathrm{OH}$ reactivities in the Pearl River Delta - China in summer 2006: measurement and model results, Atmos. Chem. Phys., 10, 11243-11260, doi:10.5194/acp-10-11243-2010, 2010.

Misztal, P. K., Heal, M. R., Nemitz, E., and Cape, J. N.: Development of PTR-MS selectivity for structural isomers: Monoterpenes as a case study, Int. J. Mass Spectrom., 310, 10- 19, 2012. 
Nakashima, Y., Kato, S., Greenberg, J., Harley, P., Karl, T., Turnipseed, T., Apel, E., Guenther, A., Smith, J., and Kajii, Y.: Total $\mathrm{OH}$ reactivity measurements in ambient air in a southern Rocky Mountain ponderosa pine forest during BEACHON-SRM08 summer campaign, Atmos. Environ., 85, 18, doi:10.1016/j.atmosenv.2013.11.042, 2014.

Nölscher, A. C., Williams, J., Sinha, V., Custer, T., Song, W., Johnson, A. M., Axinte, R., Bozem, H., Fischer, H., Pouvesle, N., Phillips, G., Crowley, J. N., Rantala, P., Rinne, J., Kulmala, M., Gonzales, D., Valverde-Canossa, J., Vogel, A., Hoffmann, T., Ouwersloot, H. G., Vilà-Guerau de Arellano, J., and Lelieveld, J.: Summertime total $\mathrm{OH}$ reactivity measurements from boreal forest during HUMPPA-COPEC 2010, Atmos. Chem. Phys., 12, 8257-8270, doi:10.5194/acp-12-8257-2012, 2012.

Pollmann, J., Ortega, J., and Helmig, D.: Analysis of Atmospheric Sesquiterpenes: Sampling Losses and Mitigation of Ozone Interferences, Environ. Sci. Technol., 39, 9620-9629, 2005.

Purvis, R., Hopkins, J., Lewis, A., Andrews, S., Punjabi, S., Bauguitte, S., Lee, J., Palmer, P., and Parrington, M.: Biogenic VOCs including monoterpenes and functionalized aromatic compounds within mid-troposphere boreal biomass burning plumes, EGU General Assembly 2013, EGU2013-1389, 2013.

Rhoderick, G. C. and Lin, J.: Stability Assessment of Gas Mixtures Containing Monoterpenes in Varying Cylinder Materials and Treatments, Anal. Chem., 85, 4675-4685, 2013.

Rinne, J., Ruuskanen, T. M., Reissell, A., Taipale, R., Hakola, H., and Kuumala, M.: On-line PTR-MS measurements of atmospheric concentrations of volatile organic compounds in a European boreal forest ecosystem, Boreal Environ. Res., 10, 425-436, 2005.
Sillman, S.: The relation between ozone, NOx and hydrocarbons in urban and polluted rural environments, Atmos. Environ., 33, 1821-1845, 1999.

Sinha, V., Williams, J., Lelieveld, J., Ruuskanen, T., Kajos, M., Patokoski, J., Hellen, H., Hakola, H., Mogensen, D., Boy, M., Rinne, J., and Kulmala, M.: OH Reactivity Measurements within a Boreal Forest: Evidence for Unknown Reactive Emissions, Environ. Sci. Technol., 44, 6614-6620, doi:10.1021/es101780b, 2010.

Taraborrelli, D., Lawrence, M. G., Crowley, J. N., Dillon, T. J., Gromov, S., Grosz, C. B. M., Vereecken, L., and Lelieveld, J.: Hydroxyl radical buffered by isoprene oxidation over tropical forests, Nat. Geosci., 5, 190-193, doi:10.1038/ngeo1405, 2012.

Wells, J. R., Gas-Phase Chemistry of $\alpha$-Terpineol with Ozone and OH Radical: Rate Constants and Products, Environ. Sci. Technol., 39, 6937-6943, 2005.

White, R. L.: Fast GC with a Small Volume Column Oven and Low Power Heater, Chromatographia, 69, 129-132, 2009.

Yassaa, N., Custer, T., Song, W., Pech, F., Kesselmeier, J., and Williams, J.: Quantitative and enantioselective analysis of monoterpenes from plant chambers and in ambient air using SPME, Atmos. Meas. Tech., 3, 1615-1627, doi:10.5194/amt-31615-2010, 2010. 